\title{
Morphology of bottom surfaces of glacier ice tongues in the East Antarctic region
}

\author{
Cesidio Bianchi $\left({ }^{1}\right)$, Massimo Chiappini $\left({ }^{1}\right)$, Ignazio E. Tabacco $\left({ }^{2}\right)$, Andrea Passerini $\left({ }^{3}\right)$, \\ Achille Zirizzotti (') and Enrico Zuccheretti (') \\ (') Istituto Nazionale di Geofisica e Vulcanologia, Roma, Italy \\ ${ }^{2}$ ) Università di Milano, Sezione Geofisica, Milano, Italy \\ (3) Università di Milano Bicocca, Dipartimento di Fisica, Milano, Italy
}

\begin{abstract}
During three Antarctic summer campaigns (1995/97/99) Radio Echo Sounding (RES) system data from some glacier ice tongues in the East Antarctic regions between Victoria Land and George V Land were collected. The morphology and structure of the bottom surfaces deduced from the electromagnetic interpretation of echo signal were observed. The bottom surfaces at the ice/water interface show either irregular or flat contours or both. Some ice tongues are nearly perfectly flat, others show clear signs of irregularities while three of them have good regular spaced rippled bottom surfaces. The latter structures are well-evident in the longitudinal traverse of the tongues, whereas the transversal paths do not show the same features. This particular shape of the bottom surfaces related to the ablation process and detachment mechanism could be interesting especially to determine some physical characteristics and the possible fracture points of the ice tongues.
\end{abstract}

Key words radio echo sounding - radio glaciology-glacier ice tongues

\section{Introduction}

The continuous ice flow from the continent to the sea maintains close to equilibrium the mass balances of the Antarctic ice sheet and compensates the ice mass inputs due to the snow accumulation. The mass of the ice is transported by glaciers and ice streams. The glacier ice tongues, that can reach several tens of kilometres, are the terminal parts of this ice flow. Moreover, they are one of the most relevant

Mailing address: Dr. Cesidio Bianchi. Istituto Nazionale di Geofisica e Vulcanologia, Via di Vigna Murata 605, 00143 Roma, Italy; c-mail: bianchi@ingv.it geophysical phenomena observable in the Antarctica coast line.

Understanding the physical properties of the flow regime is important to evaluate the short term evolution of mass balance and the glacier ice tongues are key tools for comprehension of the whole process. RES (Radio Echo Sounding) is a powerful technique to visualise the morphology of the ice glacier tongue bottom surfaces; it provides useful information on complex problems related to the study of mass balance.

Three RES campaigns (1995/97/99) were performed in the East Antarctic regions between Victoria Land and George V Land (fig. 1) with the aim of collecting and presenting the bottom surfaces of the main glacier ice tongues in the investigated area.

The RES system employed (Tabacco et al., 1999) operates at $60 \mathrm{MHz}$ with $16 \mathrm{MHz}$ bandwidth with a pulse length switchable between 


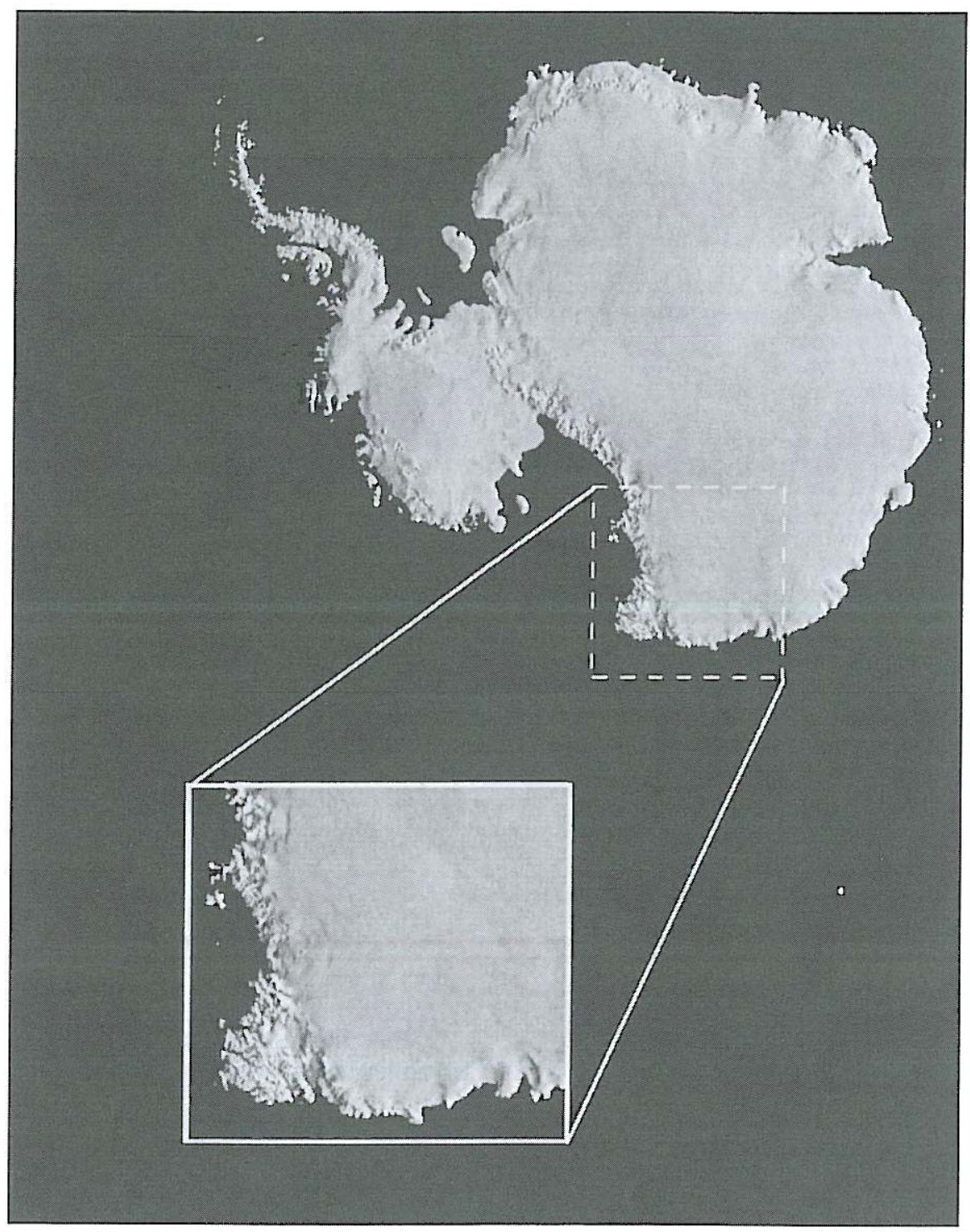

Fig. 1. East Antarctica region explored by means of the RES.

$0.25 \mu \mathrm{s}$ and $1 \mu \mathrm{s}$. The $2 \mathrm{~kW}$ of transmitted power allows us to obtain a detectable echo signal at the input of the receiver. This active remotesensing technique allows the measurements of the ice thickness of the glacier tongues in large areas by means of airborne radar. The received analog echo signal (listening time 51.2-64 $\mu \mathrm{s}$ that means a range of $4.3-5.3 \mathrm{~km}$ in the ice) is digitized at the sampling frequency of $20 \mathrm{MHz}$ with a range resolution of about $8 \mathrm{~m}$, so the bottom surface profiles can be determined with sufficient accuracy for our purpose. The ac- 
Table I. List of the glacier ice tongues with the year of measurement, the shape of the bottom surface, the longitudinal examined profile (length of RES profile) and thickness at grounding line.

\begin{tabular}{ccccc}
\hline Tongues & Year & $\begin{array}{c}\text { Bottom surface } \\
\text { morphology }\end{array}$ & $\begin{array}{c}\text { Longitudinal extension } \\
\text { in km of the examined } \\
\text { profile at the epoch of } \\
\text { the measurement }\end{array}$ & $\begin{array}{c}\text { Approximate } \\
\text { thickness in m at } \\
\text { grounding line }\end{array}$ \\
\hline Harbord & 1997 & Flat & 12.5 & 441 \\
Clark & 1997 & Flat & 20 & 562 \\
Drygalski & 1997 & Rippled & 120 & 1600 \\
Campbell & 1997 & Rippled & 22.5 & 701 \\
Aviator & 1995 & Rippled & 42.5 & 1428 \\
Mawson & 1997 & Moderate irregularities & 49 & 722 \\
Priestley & 1997 & Moderate irregularities & 20 & 420 \\
Mertz & 1999 & Moderate irregularities & 90 & 1226 \\
Mariner & 1995 & Flat & 35 & 1209 \\
Ninnis & 1999 & Not defined & 50 & 655 \\
\hline
\end{tabular}

quired data files have a header with the actual position and time obtained from a GPS receiver directly interfaced with the acquisition unit of the RES system. The horizontal sampling rate has changed in time; in the 1995 summer campaign after an on-line average operation it was about 0.3 trace $/ \mathrm{s}$ (about 6 trace $/ \mathrm{km}$ ), while in the 1997 and 1999 campaigns it was 10 trace/s (about 17 trace $/ \mathrm{km}$ ). The explored glacier ice tongues are located in the marked area in fig. 1 and a list indicating the glaciers with their main characteristics is reported in table I. In this table it is also qualitatively indicated which kinds of bottom surfaces are prevalent.

The glacier ice tongues presented are very different as extensions, thickness and other physical properties and the measurements were taken in different years. In any case, it could be interesting to present the data and the results of RES campaigns useful also for other studies and researches as this is the main purpose of the paper.

\section{Morphology of the bottom surfaces}

To determine the ice thickness and the bottom morphology of floating ice tongues, echo delay and amplitude rough values from RES measurements were scaled. The shape of the bottom surfaces of each ice tongue was obtained assuming that the deepest reflections are due to the ice/seawater interface far from the grounding line and ice/bedrock interface in the continent. In particular, the morphology of the bottom surfaces and the thickness as time delay analysis results were evaluated, assuming a radio wave velocity in the ice of about 168 $\mathrm{m} / \mu \mathrm{s}$ (Patterson, 1981, Bogorodsky et al., 1985).

The analysis of the signal amplitude along the horizontal profile does not show variation in the case of flat bottom surfaces while in the case of irregular bottom surface the recorded amplitude is variable throughout the profile. In a few cases the glacier ice tongues show rippled bottom surfaces that exhibit both concave and convex faces, producing a focusing or defocusing effect recognised in the amplitude variation in the echo signal.

The authors demonstrated (Tabacco et al., 2000 ) that, apart from fixed radio propagating contributions, the gain/loss of the received amplitude due to the geometrical shape of the reflecting surfaces can be easily calculated. The results of this time analysis are shown in figs. $2 a-j$ where the arrows indicate the termination of the glacier ice tongues. The examined profile (that is not the real extension of the 


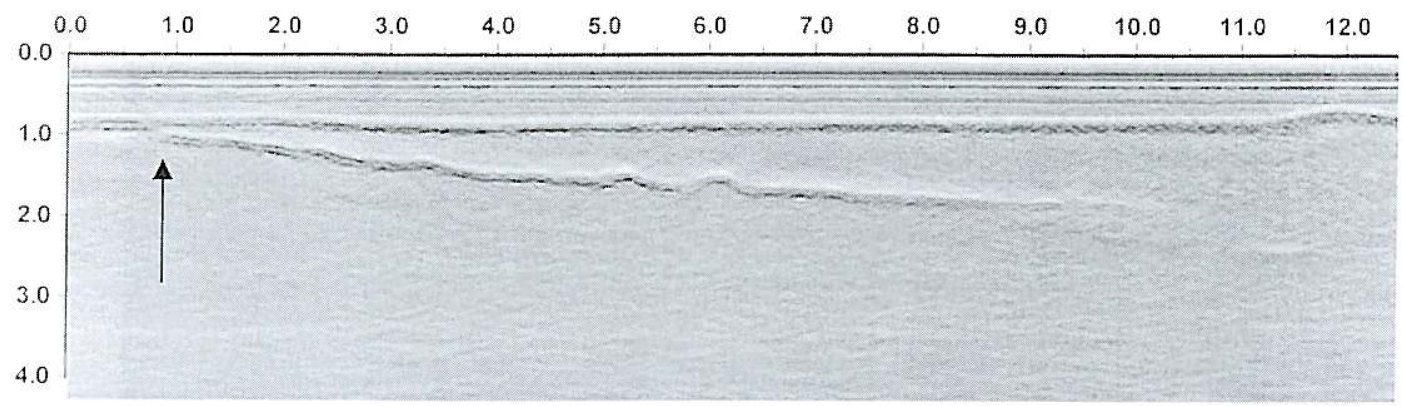

Fig. 2a. Harbord ice tongue morphology.

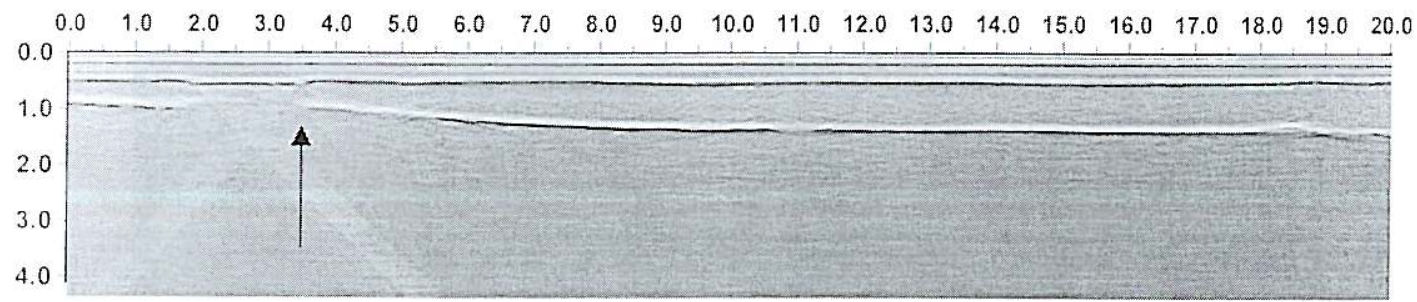

Fig. 2b. Clark ice tongue morphology.

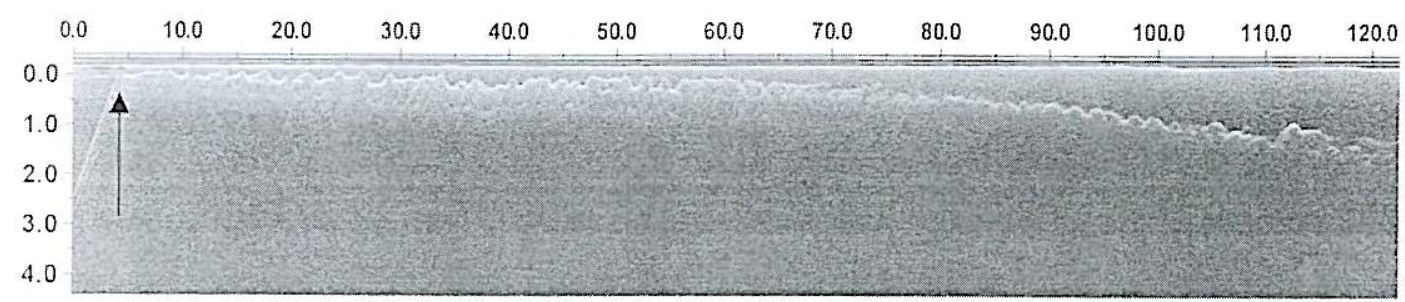

Fig. 2c. Drygalski ice tongue morphology.

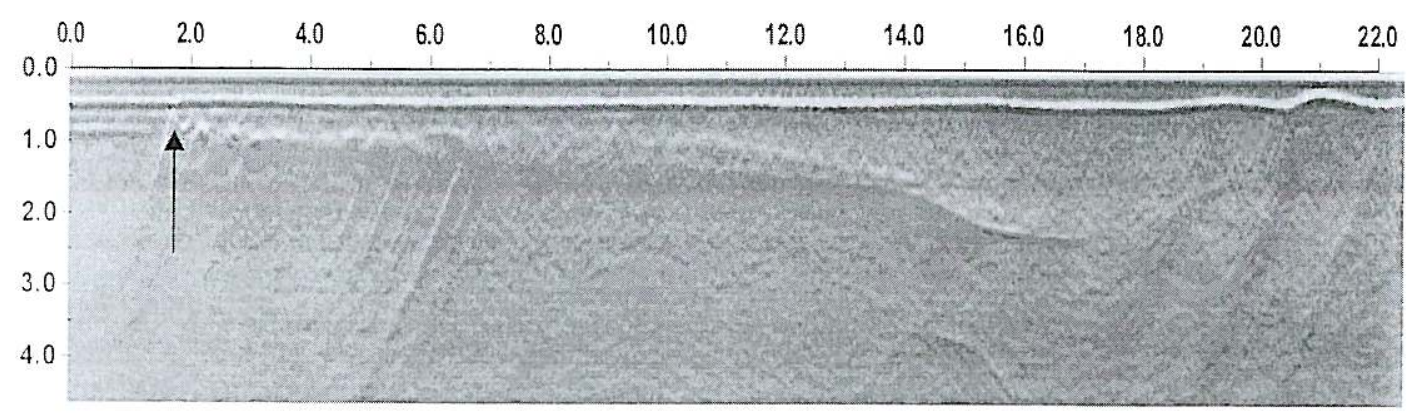

Fig. 2d. Campbell ice tongue morphology. 


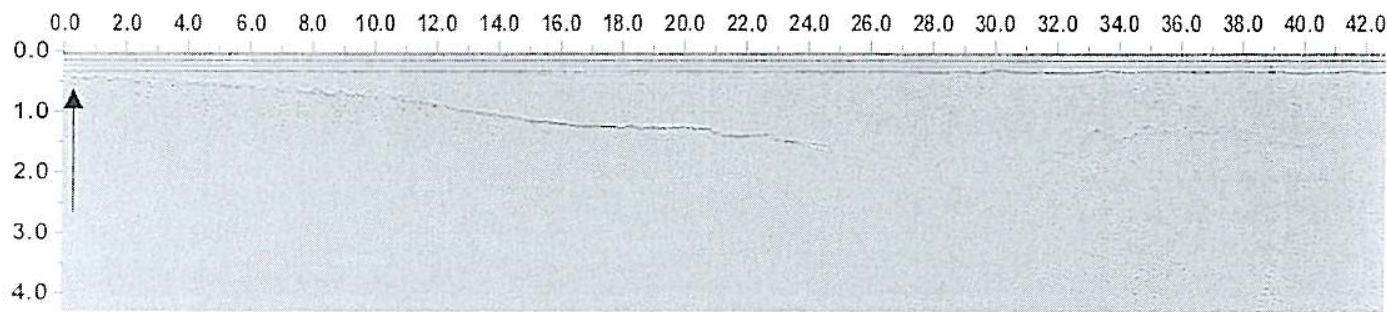

Fig. 2e. Aviator ice tongue morphology.

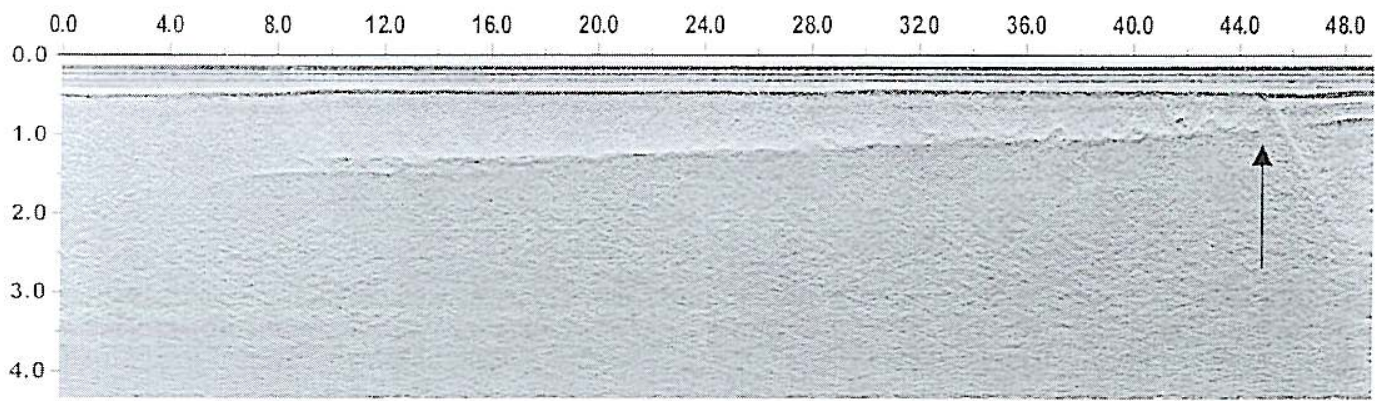

Fig. 2f. Mawson ice tongue morphology.

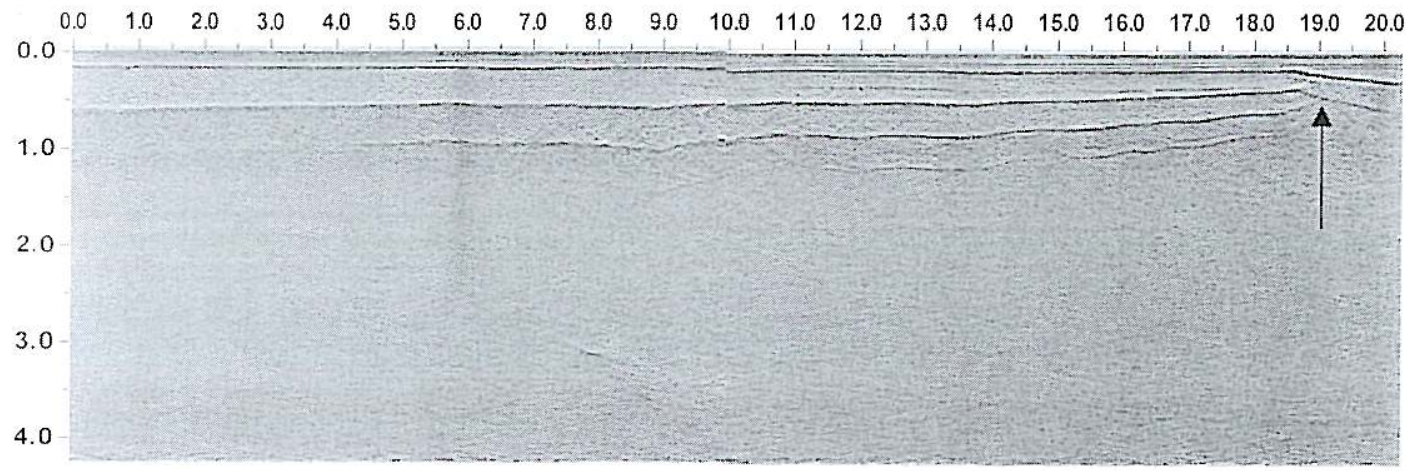

Fig. 2g. Priestley glacier morphology.

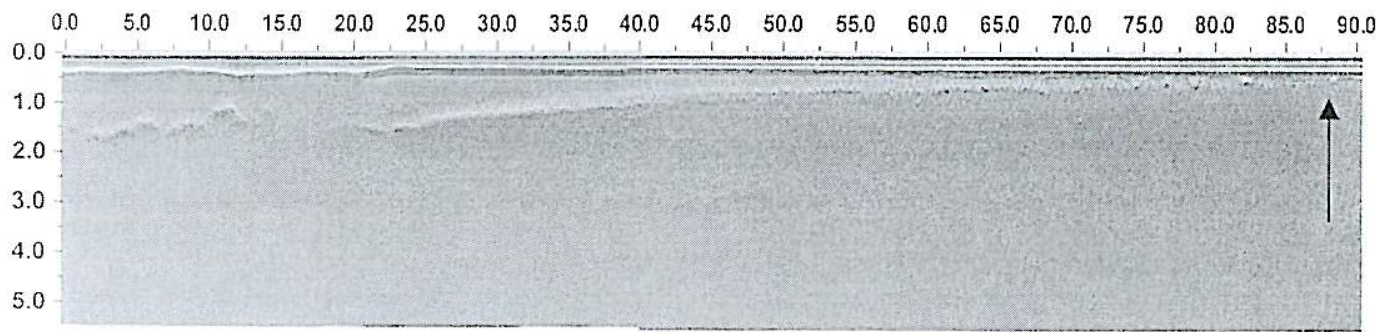

Fig. 2h. Mertz ice tongue morphology. 


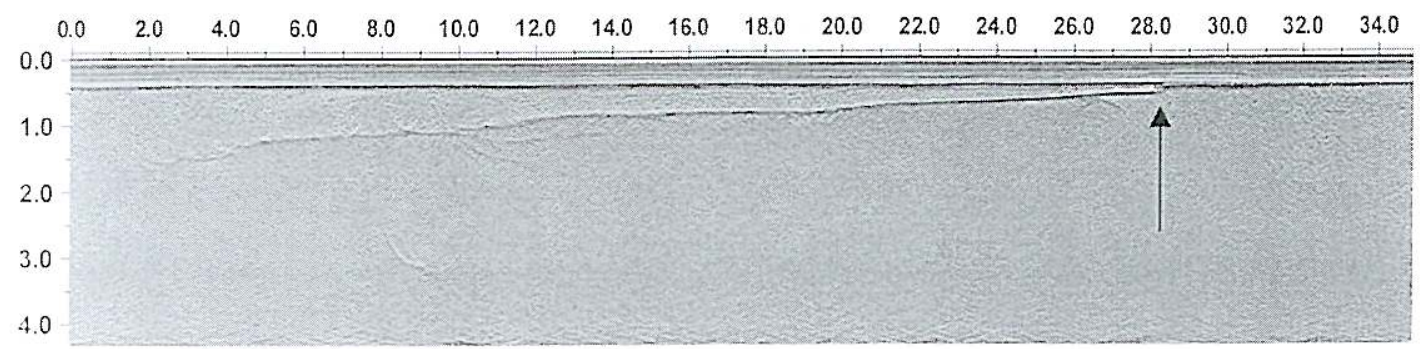

Fig. 2i. Mariner ice tongue morphology.

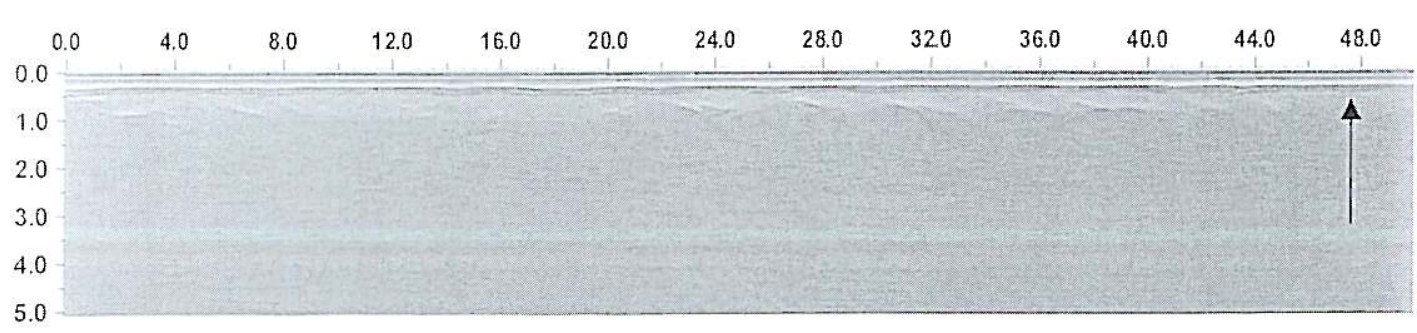

Fig. 2j. Ninnis ice tongue morphology.

tongues) and thickness are reported in table I. Except for Ninnis glacier that has a not well defined surface because of many diffraction points in the recorded echoes by RES, three kinds of bottom surfaces were observed. Clarke, Priestley and Mariner have an extremely flat surface along the whole horizontal longitudinal profile. Harbord, Mawson and Mertz have a nearly flat surface and little marked irregularities are evident. Drygalski, Campbell and Aviator show nearly regular rippled surfaces.

The examined tongues have different thicknesses starting from $441 \mathrm{~m}$ to $1600 \mathrm{~m}$ and quite different extensions ranging from $12.5 \mathrm{~km}$ to $120 \mathrm{~km}$ as well as the ice flux and the age. In the above group of figures it can be observed that, in general, the extremities of the tongues show much more marked irregularities compared with the beginning of the tongue at grounding line. This fact seems to suggest that ablation of the process is responsible for this particular morphology and this process depends on other physical properties of the glacier, the geographical position and the sea circulation.

\section{Amplitude analysis of the signal}

The received signal amplitude was evaluated, assuming knowledge of some physical electromagnetic quantities (Bogorodsky et al., 1985) such as the dielectric complex permittivity of the ice, sea ice and sea water and the temperature of the glaciers. It is also shown that the recorded amplitude variations are mainly related to the geometry of the observed bottom rippled surface.

The amplitude analysis also confirms that the observed surface morphology and thickness derived from the time scaling of data is correct within the above mentioned errors and no other radio propagating phenomena or different media like sea-water ice are involved. For the three glaciers with the bottom rippled surfaces, a further analysis taking into account the amplitude of the signal at the input of the receiver of the RES was done.

The signal amplitude variation of the echo signal reflected at the ice-seawater interface was evaluated along the horizontal profile. In order 
to determine this variation all the following quantities have been expressed in $\mathrm{dB}$. The absorption $L a$ and the geometrical attenuation $L g$ are easily evaluated knowing the arrival time from the ice surface and the bottom surface. Moreover, the electromagnetic quantities that characterise the medium are here considered constant and contribute to calculate $L a$ and $L g$ (Tabacco et al., 2000). For the same reasons, the reflection-transmission coefficients $L_{R-T}$ are also considered known at two air/ice and ice/seawater interfaces. The calibration test had been performed to evaluate the antenna gain $G_{a}$ at the operating frequency of $60 \mathrm{MHz}$ and, knowing the transfer function of the receiver it is possible to determine the received signal power $P r$. Therefore, under the same transmitted Pt, only the contributions due to the surface shape will remain. The amplitude variation $\Delta A$ is calculated by the following expression:

$$
\Delta A=+P t+G_{A}-P r-L_{R-T}-L g-L a \quad[\mathrm{~dB} \mid .
$$

Theoretically in the case of a flat surface, of homogeneous media and of a perfect calibration $\Delta A$ must be zero along the whole profile.

The scaled value of $t 1$ and $t 2$ of the longitudinal profiles of the Drygalski ice tongue $(90 \mathrm{~km})$ representing respectively the ice surface and rippled bottom surfaces are shown in fig. 3a. It has been estimated that the ice thickness ranges between $150-1500 \mathrm{~m}$ and nearly regularly rippled bottom surfaces show quasi waves with a spatial length of about $2 \mathrm{~km}$, and with a depth variation compared with the general surfaces' trend of about 150-200 m. Figure 3b

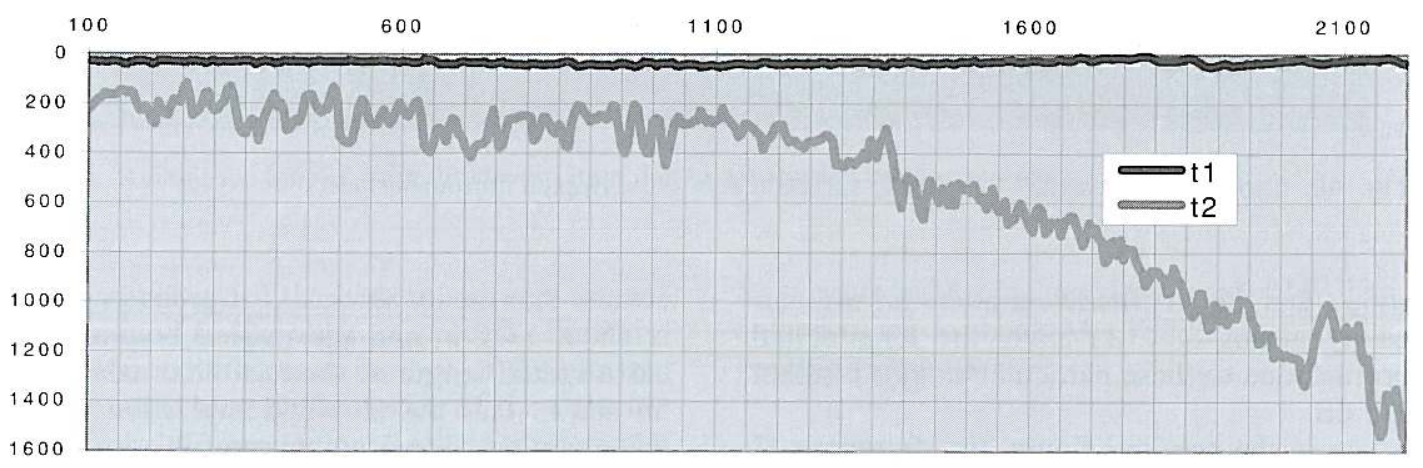

Fig. 3a. Drygalski ice tongue - scaled values of the two surfaces.

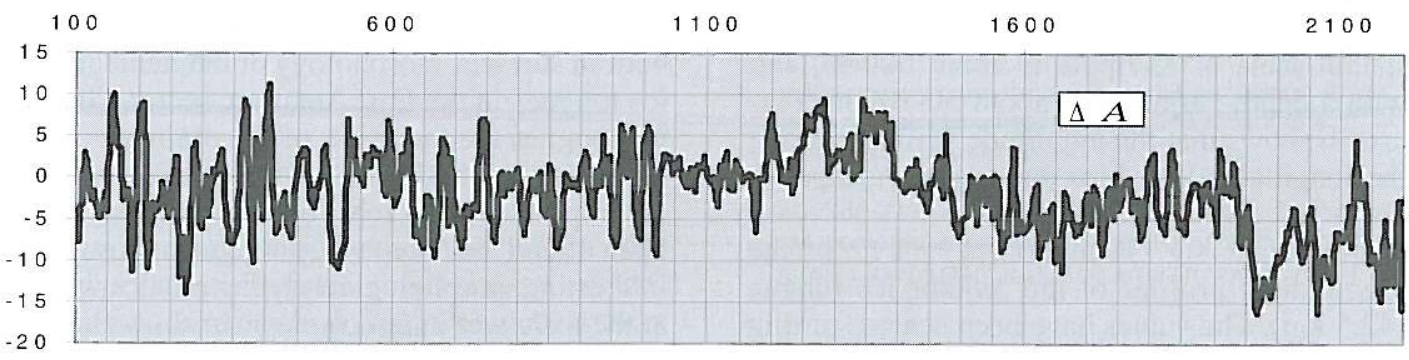

Fig. 3b. Drygalski ice tongue - amplitude variation due to the rippled bottom surface. 


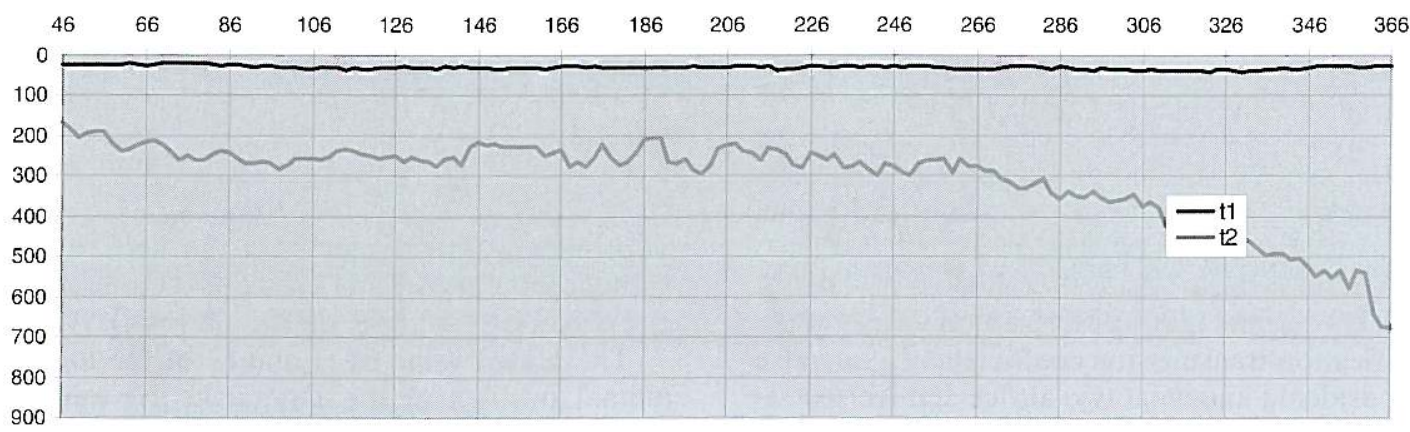

Fig. 4a. Campbell ice tongue - scaled values for the two surfaces.

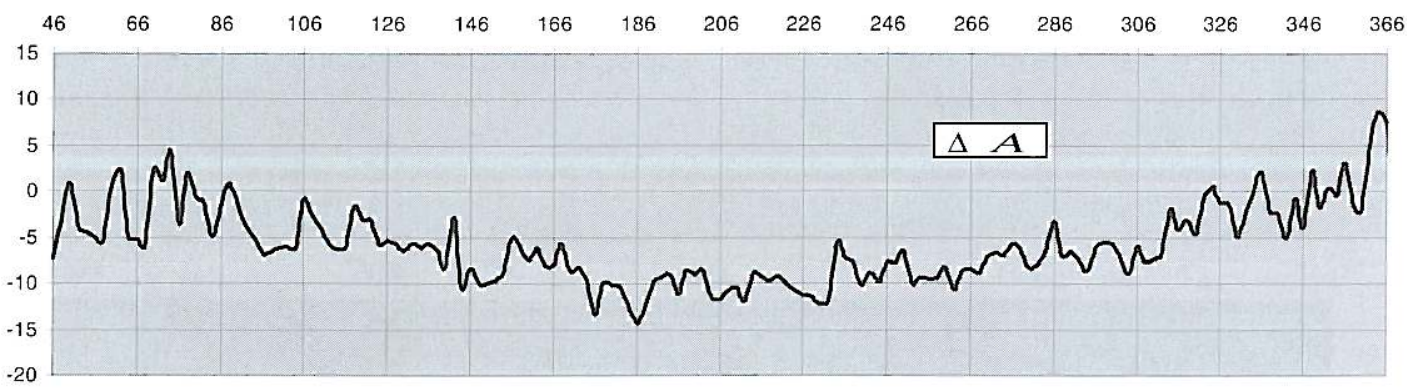

Fig. 4b. Campbell ice tongue - amplitude variation due to the rippled bottom surface.

shows that the amplitude variation $\triangle A$ evaluated by means of (3.1) along the longitudinal profiles due to these particular shapes is about $\pm 6 \mathrm{~dB}$.

As in the previous figure, fig. 4 a reports $t 1$ and $t 2$ of the longitudinal profiles of the Campbell ice tongue $(15.5 \mathrm{~km})$. The values have been scaled starting from the trace 46 to trace 446 where the rippled surface is well evident. It has been estimated that the ice thickness at grounding line is about $701 \mathrm{~m}$ and on average the spatial scale of $t 2$ ripple is about $500 \mathrm{~m}$, and with a depth variation of about $50-100 \mathrm{~m}$. Figure $4 \mathrm{~b}$ shows that the amplitude variation along the longitudinal profiles due to these shapes is about $\pm 5 \mathrm{~dB}$.

As above, fig. 5a reports $t 1$ and $t 2$ of the longitudinal profiles of the Aviator ice tongue $(42.5 \mathrm{~km})$. The values have been scaled starting from the trace 11 to trace 181 where the rippled surfaces are well evident. It has been here cal- culated that the ice thickness at grounding line is about $1428 \mathrm{~m}$ and the rippled bottom ( $t 2)$ has a spatial length of about $80-900 \mathrm{~m}$. Figure $5 \mathrm{~b}$ shows that the amplitude variation along the examined longitudinal profiles is about $\pm 10 \mathrm{~dB}$.

\section{Conclusions}

The purpose of this paper is to present the bottom surfaces morphology of the main glacier ice tongues in the East Antarctic sector. Glacier ice tongues are the result of the drainage of the ice from the continent and for this reason they are important in the mass balance process. It has been found that many ice tongues show very interesting morphological characteristics; in fact at the ice/water interface they can show flat and irregular surfaces and in some cases the bottom surfaces present a well spaced rippled trend. 


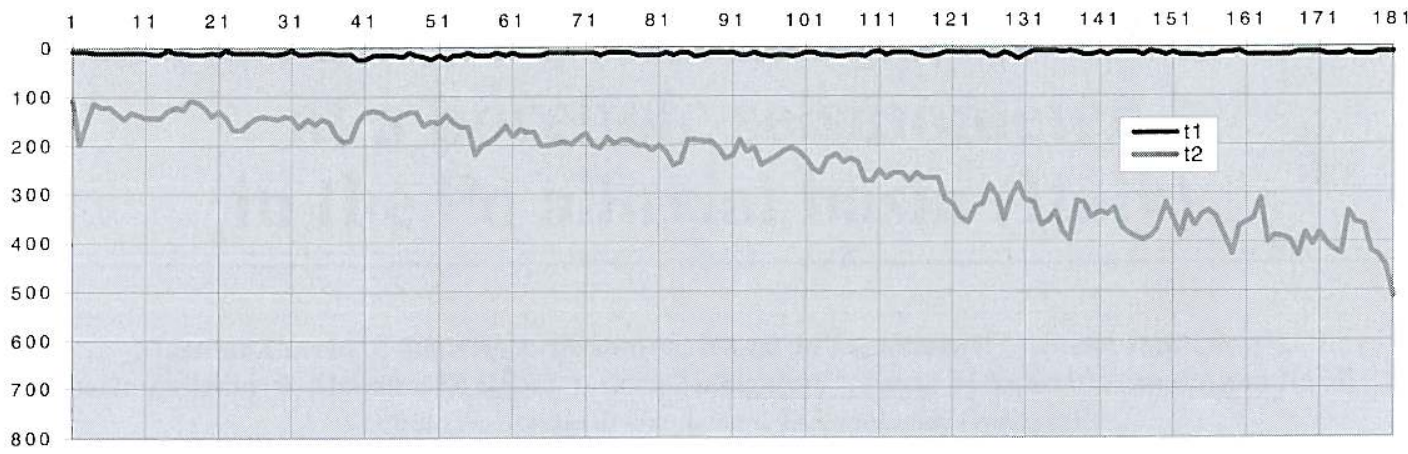

Fig. 5a. Aviator ice tongue - scaled values for the two surfaces.

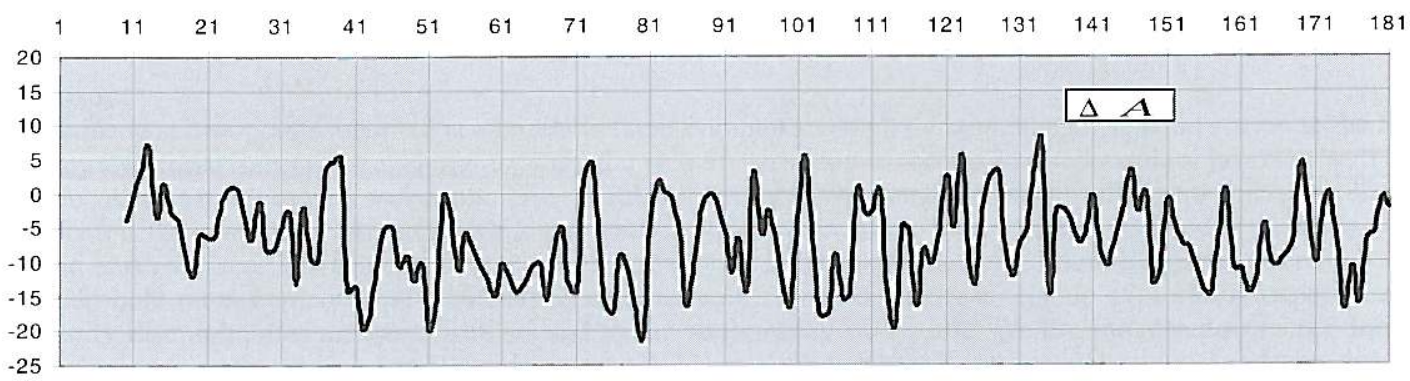

Fig. 5b. Aviator ice tongue - amplitude variation due to the rippled bottom surface.

The morphology of the bottom surfaces seems to be related to the ablation process. For this reason the ice thickness, the age of the glacier and the stretching at the epoch of the detachment from the grounding line are important. The geographical position and sea-water circulation can contribute to the formation of the mentioned structures as well as other physical quantities such as temperature, viscosity etc., that are expected to be involved in the process of ablation responsible for the irregularities of bottom surfaces.

\section{Acknowledgements}

This research was carried out within the framework of a Project of Glaciology of the Programma Nazionale di Ricerche in Antartide (PNRA) and was financially supported by ENEA. The comments of Dr. Angelo De Santis have improved the manuscript considerably. The authors wish to thank Mrs. Silvia Pau for the graphic elaboration.

\section{REFERENCES}

BOGORODSKY, V.V., C.R. BENTLEY and P.E. GUDMANDSEN (1985): Radioglaciology (Reidel Publ. Company), pp. 254.

PATTERSON, W.S.B. (1981): The Physics of Glaciers (Pergamon Press), second edition, pp. 234.

Tabacco, I.E., C. Bianchi, M. Chiappini, A. Passririni, A. ZirizzoTTI and E. ZuCCHERETTI (1999): Latest improvements for the echo sounding system of the Italian radar glaciological group and measurements in Antarctica, Ann. Geofis., 42 (2), 271-276.

TABACCO, I.E., C. BIANCHI, M. ChiAppini, A. ZIRIZZOTTI and E. ZuCCHERETTI (2000): Analysis of bottom morphology of the David-Drygalski glacier Ross Sea Coast Line (Antaretica), Ann. Glaciology, 30, 47-51.

(received September 12, 2000; accepted January 10, 2001) 